\title{
Training for trauma
}

\section{Preventing crashes-open-access educational resources for health care emergencies}

\author{
Aaron Gross, Julianne Zandberg, David LaPierre \\ Faculty Reviewer: Lisa Shepherd, MD (Division of Emergency Medicine)
}

\begin{abstract}
Appropriate training in the management of trauma is important for medical students. Preventing Crashes is a program created to provide new educational opportunities for learners and clinicians, in community settings, to develop competence in managing trauma. This article discusses the rationale, features, and planned implementation of the Preventing Crashes program.
\end{abstract}

\section{INTRODUCTION}

Trauma is the main cause of death in Canadians aged 1 to $3,{ }^{1}$ and $15 \%$ of the population suffered an injury severe enough to limit their function in 2009-an increase from $13 \%$ in $2001 .^{2}$ Medical learners in the Emergency Department (ED) will have seen the elderly woman who had a fall, the teenage boy with a concussion, and the child with a lacerated finger. However, there is far less training for trauma encountered in other environments, such as clinics, public spaces, or the wilderness. Clinicians of all types will see trauma in these non-ED settings. Although specialized trauma training is unnecessary for most physicians, it is important to gain basic competency in managing trauma outside the ED.

Education devoted to trauma in the pre-clerkship years of many medical schools is limited. An analysis of Harvard Medical School's 2015 curriculum revealed that in the first two years, only 6.5 hours of teaching were focused on trauma, while 128 hours was devoted to heart disease. ${ }^{3}$ In the UK, the average graduating student receives less than five hours of trauma teaching, and $62 \%$ of students have no training on cervical spine immobilisation both in lecture and bedside teaching. ${ }^{4}$

There are several courses available for training in trauma, though they typically are costly to run and have limited availability, especially for repeat practice. Advanced Trauma and Life Support (ATLS) is typically attended by residents or clinicians, though senior medical students have also benefitted from this course. ${ }^{5}$ The Trauma Association of Canada offers courses which expand on ATLS, while the American College of Surgeons offers a simplified version for medical students (TEAM). ${ }^{6}$ This article introduces Preventing Crashes, an interprofessional, low cost training program helping students and health care providers build and maintain clinical competence in treating trauma and other life-threatening emergencies.

\section{HISTORY AND LEARNING MODEL}

Originating in Chatham-Kent, Preventing Crashes was designed to provide ongoing training opportunities following cer- tificate courses such as Advanced Cardiovascular Life Support (ACLS), assisting with solidification and maintenance of clinical competence. It initially focused on cardiovascular emergencies on the inpatient hospital floor, and has since expanded to include other emergencies, including trauma.

Preventing Crashes focuses on building training capacity within rural and sub-urban communities. The Preventing Crashes model uses principles of adult learning, including the flipped classroom (pre-reading before the session), case-based learning, skills stations, and hybrid simulations (actors and mannequins used together). Resources and approaches are designed to be easy and cost-effective. The program has been piloted with success in both Canada and Uganda. The model promotes high fidelity training, meaning it attempts to closely mimic actual clinical experiences. However, recommended simulators are also low-technology, resulting in an initial and operational budget that is feasible in today's economic climate. Lastly, the model uses both expert and peer facilitators to further expand training capacity, while reducing costs. Resources are published under an Open Access license, permitting widespread adoption and customization for local contexts.

The Preventing Crashes site provides a series of options for low-technology, high-fidelity simulators to allow practice with a range of clinical scenarios and procedures, including: basic life support, advanced and surgical airway management, chest tube placement, and venous and intraosseous access. For example, chest tube insertion may be practiced with a manikin (Fig 1) or section of pig ribs (Fig 2), with skin intact.

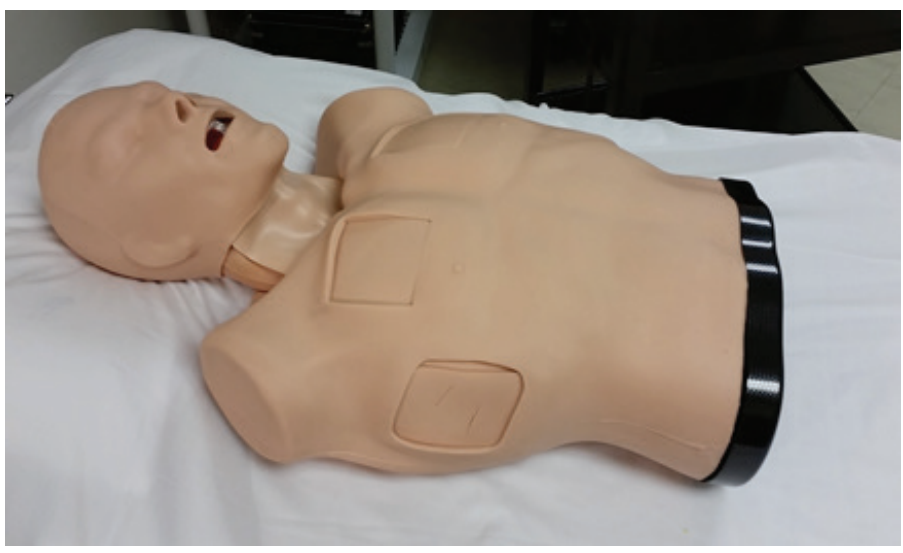

Figure 1. Truman Trucorp manikin-allows chest tube insertion, cricothyroidotomy, needle decompression. 


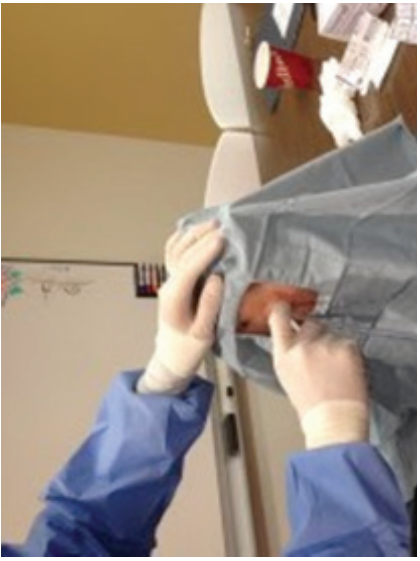

Figure 2. Pig ribs skills trainer for chest tube insertion.

\section{CURRICULUM}

Our initial trauma module is focused on non-health care settings, with a subsequent ED module to follow. Inspired by other curricula (described in references 6 and 7), current topics are listed in Table 1.

We also make recommendations for students or providers to consider including a first aid kit for their home or car, provided at preventingcrashes.ca/first-aid-kit.

While a wide array of students, residents, and clinicians have contributed to our resources to date, we are currently working with a small group of Schulich Medicine students to develop our trauma learning resources. These are then reviewed by expert clinicians for content and style as they are published to our site. All resources are published using an Open Access license.

Table 1: Preventing Crashes trauma curriculum

\begin{tabular}{cccc}
\hline Causes & Anatomical & Assessment & Management \\
\hline $\begin{array}{c}\text { penetrating injury } \\
\text { blunt force injury } \\
\text { blast injury } \\
\text { near drowning } \\
\text { hypothermia }\end{array}$ & $\begin{array}{c}\text { head and neck } \\
\text { chest }\end{array}$ & $\begin{array}{c}\text { scene survey } \\
\text { primary survey }\end{array}$ & $\begin{array}{c}\text { spinal immobilization } \\
\text { airway management } \\
\text { secondary survey }\end{array}$ \\
& & $\begin{array}{c}\text { needle decompression } \\
\text { hemorrhage control } \\
\text { femoral fracture }\end{array}$ \\
\hline
\end{tabular}

\section{EXAMPLE CASE AND SIMULATION}

Our learning sessions typically begin with discussion cases. In this example (Figure 3), a teenager develops an arterial bleed following a bike accident.

The case may be seen in its entirety at http://preventingcrashes.ca/case-trauma-nonhealth-care-1.

The discussion case is normally followed by a simulation. A facilitator guide provides a listing of supplies required, a script for the actor, and facilitator prompts to guide simulation progression and feedback. The facilitator guide for this case is provided at

http://preventingcrashes.ca/wordpress/wp-content/uploads/2016/11/PCSim-TomHarley-Traumal-Non-HealthCare.pdf.

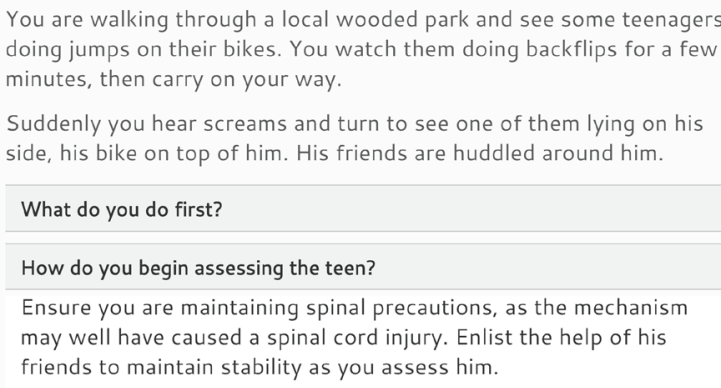

You do a quick check of his radial pulse, finding a strong, regular rate of 110 - his Circulation is grossly intact. Given the extent of bleeding from his arm, you decide to investigate the injury further. You use a pocketknife to carefully remove his jacket sleeve and find brisk, pulsatile bleeding coming from his upper arm. Beside him, you see a broken tree branch that appears to have impaled his arm; it is now free.

How do you address the bleeding?

How do you proceed with treatment?

Are there any other approaches recommended for arterial bleeding?

What do you do next?

The EMS team arrives. How do you hand over?

Figure 3. Example Preventing Crashes discussion case.

\section{PLANS FOR IMPLEMENTATION OF TRAUMA TRAINING}

The Preventing Crashes trauma module may be implemented in a variety of contexts, including undergraduate, postgraduate, and continuing education settings. We will first launch our trauma curriculum with Schulich Medicine students and residents in Chatham, and then expand according to interest in other communities supporting Schulich trainees. Partnership with nursing and paramedic programs will also be sought, to expand training reach and offer an interprofessional dimension to sessions.

Our website continues to illustrate recent training events, and will be used to build interest from other communities. The development of training capacity for trauma will occur alongside capacity for other health care emergencies, and the purchase of appropriate simulation equipment should only be done after a thorough needs analysis has been done. Our team will assist with this process, along with planning and supporting the development of local facilitators.

Within the London and Windsor undergraduate medical settings, senior medical students may be engaged as peer facilitators after having successfully completed training sessions as learners. With appropriate support from residents and staff physicians, it is possible that training events for trauma care could be regularly offered to interested students. 


\section{CONCLUSION}

Given the high prevalence of trauma, and the potentially serious outcomes of inadequate management, proper training of medical students, residents, and physicians in a variety of settings is an important priority.

Preventing Crashes has been created to provide new educational opportunities for learners and clinicians in community settings to develop competence in managing trauma and other health care emergencies. We encourage interested communities to explore our resources and consider implementing them, and to provide feedback to strengthen our resources and approaches. Our resources are open-access and low-tech, specifically designed to have a low cost, quick setup, and to offer a high fidelity experience.

Managing trauma is not easy. Without experience in a variety of settings, competency cannot be developed. The Preventing Crashes training program aims to fill this gap, and in doing so increase the confidence of learners who may not otherwise decide to provide rural, emergency care.

\section{REFERENCES}

1. Leading causes of death in Canada. Statistics Canada Catalogue no. 84-215-XWE [Internet]. Statistics Canada; 2010 [cited 2016 December 16]. Available from: http://www5.statcan.gc.ca/olc-cel/olc.action?Ob$\mathrm{jId}=84-215-\mathrm{x} \&$ ObjType=2\&lang=en\&limit $=0$.

2. Statistics Canada. Injuries in Canada: Insights from the Canadian Community Health Survey. Statistics Canada Catalogue no. 82-624X. Statistics Canada; 2010 [cited 2016 December 16]. Available from: http://www.statcan.gc.ca/pub/82-624-x/2011001/article/11506-eng. htm.
3. Waterford SD, Williams M, Siegert CJ, et al. Trauma education in a state of emergency: a curriculum-based analysis. J Surg Res. 2015 Aug; 197(2): 236-9.

4. Mastoridis S, Shanmugarajah K, Kneebone R. Undergraduate education in trauma medicine: the students' verdict on current teaching. Med Teach. 2011; 33(7):585-7.

5. Ali J, Cohen RJ, Gana TJ, Al-Bedah KF. Effect of the advanced trauma life support program on medical students' performance in simulated trauma patient management. J Trauma. 1998; 44(4): 588-591.

6. Ali, J. The Trauma Evaluation and Management (TEAM) teaching module: its role for senior medical students in Canada. Can J Surg. 2003; 46(2):99.

7. M3 Curriculum. Clerkship Directors in Emergency Medicine (CDEM); n.d. [cited 2016 December 16]. Available at: https://cdemcurriculum. com/m3-curriculum-revisions/.

\section{Bluewater Health Sarnia \& Petrolia, Ontario}

Bluewater Health is recruiting for the following positions to provide services to the residents of Sarnia-Lambton both in the community and at the hospital:

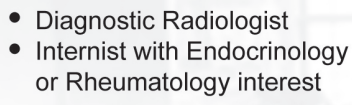

- Diagnostic Radiologist

- Internist with Endocrinology or Rheumatology interest

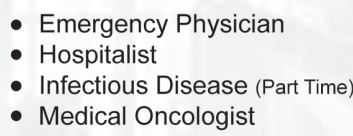

- Hospitalist

- Infectious Disease (Part Time)

- Medical Oncologist

- Neurologist

- Obstetrician/Gynaecologist

- Paediatrician

- Plastic Surgeon

Bluewater Health operates 320 beds at hospitals in Petrolia and Sarnia. We are award winning, Accredited with Exemplary Standing. We offer an array of specialized acute, complex continuing care, allied health and ambulatory care services including:

- A broad range of diagnostic services, including CT and MRI.

- Full spectrum of specialists available 24/7(neurosurgery \& interventional cardiology not available)

- Closed Critical Care Unit • District Stroke Centre • Schedule 1 Psychiatric Unit

-Affiliation with Western University's Schulich Medicine Distributed Education Network.

We are committed to improving the patient experience using engagement, Lean, and innovation.

Situated on the shores of Lake Huron at the border to Michigan,

Sarnia offers excellent quality of life, sports, arts and culture, education, state of the art health care, and beautiful natural environment.

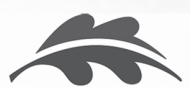

To apply, please send $\mathrm{CV}$ and references to:

Dr. Mike Haddad, Chief of Professional Staff

Bluewater Health

Email: Medical_affairs@bluewaterhealth.ca Tel: 519-464-4400 ext 4534.

\section{BLUEWATER}

H E A L T H

Life, health and renewal. 